\title{
Millennium tree-ring reconstruction of drought variability in the eastern Qilian Mountains, northwest China
}

\author{
Xiaohua Gou • Yang Deng • Linlin Gao • Fahu Chen • \\ Edward Cook $\cdot$ Meixue Yang $\cdot$ Fen Zhang
}

Received: 6 May 2014 / Accepted: 29 November 2014

(C) Springer-Verlag Berlin Heidelberg 2014

\begin{abstract}
Knowledge of natural long-term drought variability is essential for water resource management and planning, especially in arid and sub-arid regions of the world. In the eastern Qilian Mountains of China, long-term drought variability based on high-resolution proxy records such as tree-ring data are still scarce to date. Here we present a new tree-ring chronology from the eastern Qilian Mountains which provides a valuable 1,002-year record (1009-2010 $\mathrm{CE})$ of drought variability. The new reconstruction of JuneJuly 5-month scale standardized precipitation and evapotranspiration index is the first millennium tree-ring estimate of past climate developed in the eastern Qilian Mountains. The record shows that this region has experienced several persistent droughts and pluvials over the past millennium, with significantly drier climate during the fifteenth century and dramatic wetting since the nineteenth century. The low frequency generally agrees with other nearby studies based on both tree-ring data and other proxy data.
\end{abstract}

Keywords Tree-ring · Drought variability · Eastern Qilian Mountains

X. Gou $(\bowtie) \cdot$ Y. Deng $\cdot$ L. Gao $\cdot$ F. Chen $\cdot$ F. Zhang

MOE Key Laboratory of Western China's Environmental

Systems, Collaborative Innovation Centre for Arid

Environments and Climate Change, Lanzhou University, Lanzhou 730000, China

e-mail: xhgou@lzu.edu.cn

X. Gou $\cdot$ E. Cook

Tree-Ring Laboratory, Lanont-Doherty Earth Observatory

of Columbia University, Palisades, NY 10964, USA

M. Yang

State Key Laboratory of Cryospheric Sciences, Cold and Arid

Regions Environmental and Engineering Research Institute,

Chinese Academy of Sciences, Lanzhou 730000, China

\section{Introduction}

Global mean surface temperatures have risen by $0.85 \pm 0.20^{\circ} \mathrm{C}$, over the period $1880-2012$, and projections of future climate change suggest further global warming (IPCC 2013). Warming of the global climate is expected to be accompanied by increase of global precipitation, as warmer air is able to hold more water vapour (Wentz et al. 2007). However, precipitation changes are expected to differ from region to region: precipitation is likely to increase at high latitudes, the equatorial Pacific Ocean and many mid-latitude wet regions, and decrease in many already dry mid-latitude and subtropical regions (IPCC 2013).

In the arid northwest China, Shi et al. (2007) found that the region has become wetter in the last several decades. However, the data they used are typically limited in length, which hampers our understanding of the trend of long-term hydroclimatic variability in this region, and how this variability may be changing in a warming world. Therefore, long-term hydroclimatic variability derived from highresolution paleoclimatic proxy data, like tree rings, lake deposits, ice cores and historical documents, are invaluable. Among these, annually resolved and precisely-dated treering data are most commonly used. Tree-ring based hydroclimate reconstructions have been developed for numerous sites around the globe (Cook et al. 2010). However, in the eastern Qilian Mountains, the tree-ring chronologies reported so far are mostly based on Qinghai spruce (Picea crassifolia Kom.) and span less than two centuries (Deng et al. 2013), which are barely sufficient to study the patterns of climate variability at multi-decadal and centennial timescales. Luckily, Qilian juniper (Juniperus przewalskii Kom.) is also found in this region. Qilian juniper is one of the most successful tree species for dendroclimatology in northwestern China, and had been used to reconstruct the 
climate variations for the last millennium or even longer (Zhang et al. 2003; Liu et al. 2005, 2006; Shao et al. 2005, 2010; Gou et al. 2010; Yang et al. 2014).

Here we report a new tree-ring chronology of Qilian juniper, which is robust back to $1009 \mathrm{CE}$, and is currently the longest tree ring chronology develop for the eastern Qilian Mountains. This chronology documents variations of drought severity in the eastern Qilian Mountains over the last millennium. Such long-term records are essential to understanding natural climate variability and validating climate prediction models.

\section{Data and methods}

\subsection{Study area and tree-ring data}

The sampling sites are situated in the Langya valley in the eastern part of the Qilian Mountains, which is currently near the northern limit of the Asian summer monsoon (Fig. 1). The dominant tree species in this area are Qinghai spruce ( $P$. crassifolia Kom.) on the wetter, shaded slopes, and Qilian juniper (J. przewalskii Kom.) on the drier, sunnier slopes. Ring-width cores were taken from living trees at breast height $(1.3 \mathrm{~m})$ by increment borer from two Qilian juniper (J. przewalskii Kom.) sites (LYA (37.95N, 101.24E, 3,210-3,265 m a.s.1.) and LYB (37.97N, 101.26E, 3,164$3,220 \mathrm{~m}$ a.s.1.,), about $3 \mathrm{~km}$ apart. One to four cores were sampled from each tree from different directions. In total, 179 cores from 100 trees were collected (58 cores from 33 trees at LYA, and 121 cores from 67 trees at LYB) (Fig. 1).
These two sites share similar slope $\left(\sim 60^{\circ}\right)$, aspect (southfacing), soil condition (shallow soil) and elevation, so we combined all samples from these sites in the subsequent analysis.

Samples were processed using standard dendrochronological techniques (Stokes and Smiley 1968). Increment cores were air dried and glued onto wooden mounts with transverse axis up. Once dry, all cores were progressively polished with finer sandpapers to reveal the cellular structure of the wood. Each core was crossdated, each tree ring assigned the exact calendar in which it was formed. All tree-ring widths were then measured to an accuracy of $0.001 \mathrm{~mm}$ using a Velmex measuring system. The computer program COFECHA was used to ensure the accuracy of both crossdating and measurements (Holmes 1983). Cores that were too short or yielded ambiguous results were excluded from further analysis, and 144 cores from 77 trees were used to establish the chronology.

To remove or reduce non-climatic influences, measured ring-width series were detrended with negative exponential curves or straight lines, using the signal free detrending method (Melvin and Briffa 2008; Cook et al. 2013). The individual index series were then combined into a single chronology by calculating a bi-weight robust means chronology (Cook and Kairiukstis 1990). In order to account for changes in variance associated with varying sample depth through time, the variance in the chronology was stabilized using a method introduced by Osborn et al. (1997) and further developed by Frank et al. (2007). The stabilized signal-free chronology was used in the subsequent reconstruction.
Fig. 1 Map of the study region, showing the locations of the tree-ring sites and nearby meteorological stations. The modern Asian summer monsoon limit is shown by the dashed thick line (after Chen et al. 2008)

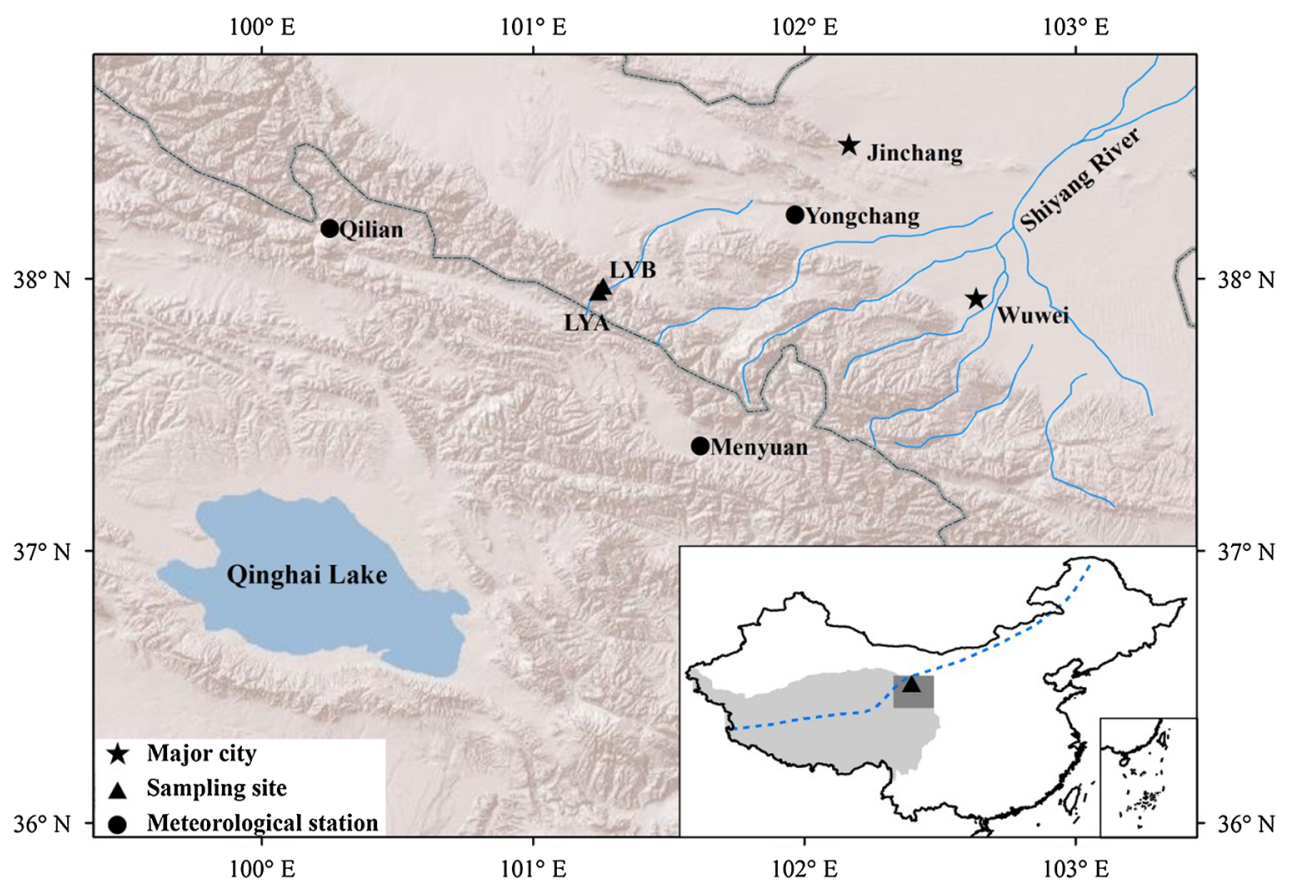


Fig. 2 Langya tree-ring width chronology. Sample size, RBAR, and EPS for the chronology are also shown. RBAR and EPS are computed the chronology is determined by the EPS value $>0.85$ using 51-year windows, lagged 1 year. The reliable portion of

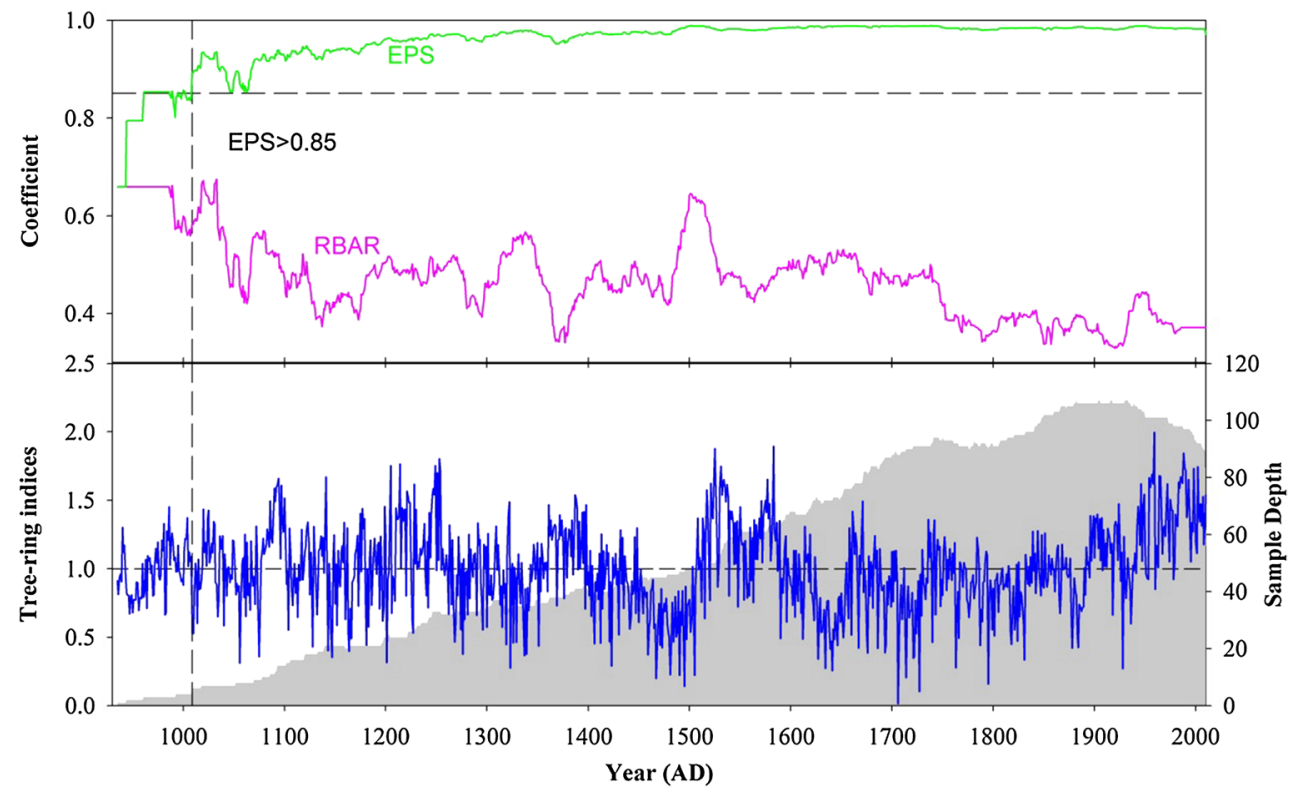

Chronology quality was interpreted using the expressed population signal (EPS) statistic; an EPS greater than 0.85 is generally considered to be an acceptable threshold for a reliable chronology (Cook and Kairiukstis 1990). In this study, running EPS and RBAR were calculated using a 51-year window that lags by 1 year. Though the chronology extends to $935 \mathrm{CE}$, the EPS does not exceed the suggested minimum threshold of 0.85 until $1009 \mathrm{CE}$, when the sample size reaches six cores (four trees). Therefore, we conclude that the reliable portion spans from 1009 to 2010 CE (Fig. 2). The mean and median segment lengths are 400 and 344 years, an indication of the ability of this record to reflect low-frequency variability on these time scales (Cook et al. 1995).

\subsection{Climate data}

The nearby weather stations to the sampling sites are Yongchang $\left(38^{\circ} 14^{\prime} \mathrm{E}, 101^{\circ} 58^{\prime} \mathrm{N}, 1,976.9 \mathrm{~m}\right.$ a.s.l., $1958-$ $2010)$, Menyuan $\left(37^{\circ} 23^{\prime} \mathrm{E}, 101^{\circ} 37^{\prime} \mathrm{N}, 2,850.0 \mathrm{~m}\right.$ a.s.l., $1956-2010)$ and Qilian $\left(38^{\circ} 11^{\prime} \mathrm{E}, 100^{\circ} 15^{\prime} \mathrm{N}, 2,787.4 \mathrm{~m}\right.$ a.s.1., 1956-2010), which are about 70, 71 and $91 \mathrm{~km}$ away from the sampling sites, respectively. Considering the large difference in the elevation between the sampling sites and Yongchang station, we only used the data from the other two stations. Mean annual temperatures (precipitation) at Menyuan and Qilian are approximately $0.8{ }^{\circ} \mathrm{C}(525.7 \mathrm{~mm})$ and $1.0{ }^{\circ} \mathrm{C}(403.7 \mathrm{~mm})$, respectively (Fig. 3). Monthly temperature and precipitation show pronounced seasonality. The warmest temperatures occur in July and the coldest in January, and the monthly total precipitation peaks in August or July, with approximately 83.4 or $90.0 \%$ occurring between May and September

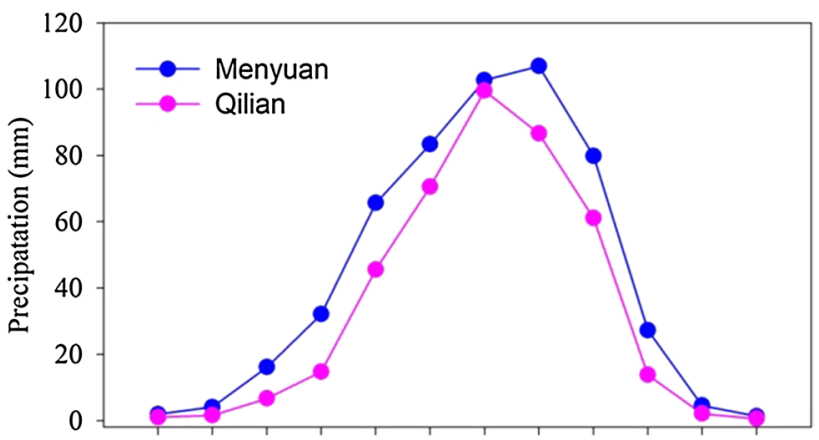

Jan Feb Mar Apr May Jun Jul Aug Sep Oct Nov Dec

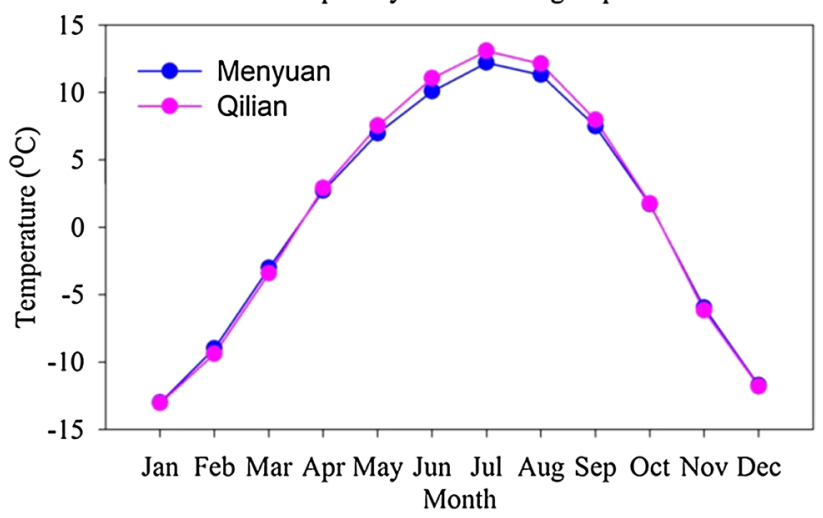

Fig. 3 Average monthly precipitation (upper) and temperature (bottom) from the Menyuan (1956-2010) and Qilian (1956-2010) meteorological stations

during the warm season. We applied the method of Jones and Hulme (1996) to develop regional series of monthly temperatures and precipitation, by using the monthly climate data from Menyuan and Qilian meteorological stations. 
Standardized precipitation and evapotranspiration indices (SPEI) (Vicente-Serrano et al. 2010) were also computed using the monthly regional climate series. The SPEI is designed to take into account both precipitation and potential evapotranspiration (PET) in determining drought. The SPEI can be calculated on a range of timescales by calculating the accumulated climatic water balance (difference between precipitation and PET) of the current month and a varying number of previous months. For example, to obtain the 6-month SPEI, the climatic water balance accumulated over the 5 months before to the current month enter into the calculation. Therefore, unlike many other drought indices, the SPEI is a multiscalar drought index. In this study, we calculated SPEI on timescales ranging from 1 to 12 months.

For the SPEI calculations, the algorithm developed by Vicente-Serrano et al. (2010) was used. The PET is calculated using the Modified-Hargreaves method by including precipitation data, which had been proven to improve the PET estimates significantly for arid regions (Droogers and Allen 2002). The SPEI were calculated using $R$ ( $R$ Core Team 2014) with the R package 'SPEI' (Beguería and Vicente-Serrano 2013).

To investigate tree growth/climate relationships, regional series of monthly temperatures, precipitation and SPEI were used.

\subsection{Statistical methods}

Correlation analysis was used to identify relationships between tree-ring widths and climatic factors. The correlations were calculated on a 'dendroclimatic year' (Fritts 1976) that begins in May of the previous growing season and ends in August of the current growing season. Because seasonally averaged climate indices may be more representative of tree growth than that of just one single month (Cook et al. 1999), various seasonal variables were constructed by averaging monthly values. The correlation coefficients of both the monthly and seasonally averaged climate indices were computed.

The reconstruction is derived from linear regression of the tree-ring chronology against the target climate data. The regression model was validated with a split calibrationverification procedure to test the quality and stability of the calibration models (Cook and Kairiukstis 1990). Several statistical measures were employed to evaluate the calibration models' stability, including Pearson's correlation coefficient (r), explained variance $\left(\mathrm{R}^{2}\right)$, adjustment explained variance $\left(R_{\text {adj }}^{2}\right)$, F value, sign test (ST), first difference sign test (ST1), the reduction of error (RE) and the coefficient of efficiency (CE). When the RE and CE exceeds zero, the calibration model shows greater skill than the mean of the instrumental data from the calibration or verification period, respectively.

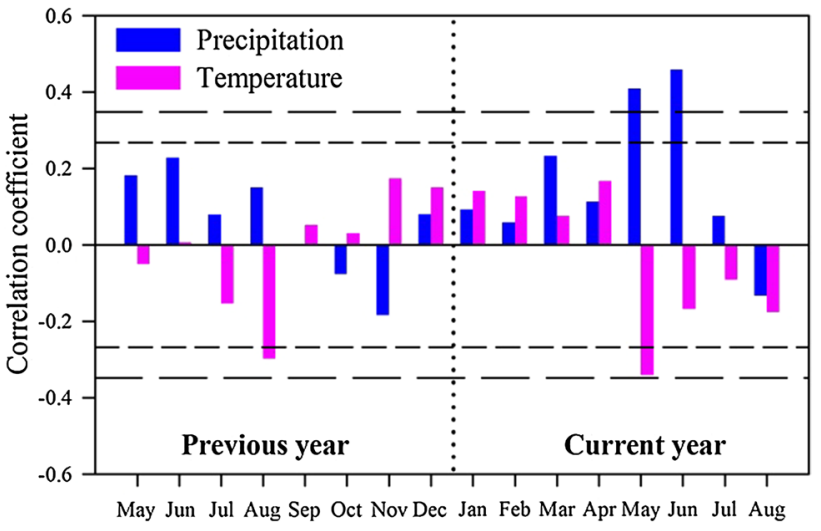

Fig. 4 Correlations of tree-ring index with monthly total rainfall and mean monthly temperature from May of the previous year to August of the current year. Short dashed and long dashed horizontal lines indicate the $p=0.05$ and $p=0.01$ significance levels, respectively

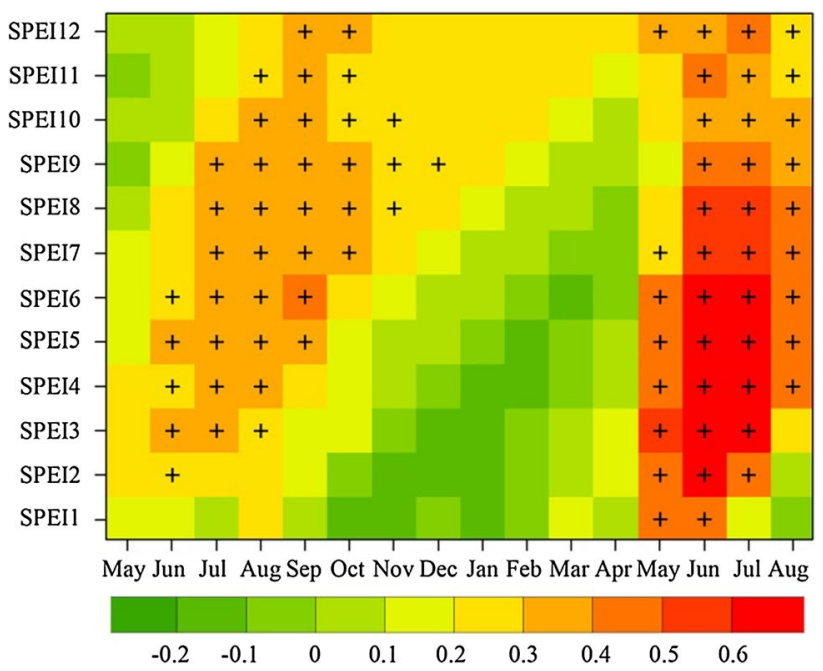

Fig. 5 Correlations of tree-ring index with monthly SPEI at different time scales. The grids with crosses indicate that the correlation is statistically significant $(p=0.05)$

Like Davi et al. (2013), the magnitude and intensity of each drought and pluvial event were also computed. Magnitude is calculated as the cumulative departure from the long-term mean for each event, and intensity is calculated as the mean cumulative departure for each event.

\section{Results}

\subsection{Climate response}

Correlation analyses between the tree-ring chronology and the climatic data show that precipitation of current May $(p<0.01)$ and June $(p<0.01)$ are significantly and positively 
correlated with the ring-width indices (Fig. 4). The negative correlations between the ring-width indices and temperature of previous August and current May are also statistically significant $(p<0.05)$. Correlations are improved with SPEI data, especially at the timescales of three to six months. As shown in Fig. 5, the correlation coefficients between tree growth and SPEI at the timescales of 3-6 months are above 0.6 for June and July. For the seasonally averaged climate indices, the highest correlation was found between tree rings and the seasonalized 5-month scale SPEI in June-July $(r=0.704)$. Therefore, the June-July 5-month scale SPEI was identified as the most appropriate predictand for the reconstruction.

\subsection{Calibration and verification of the reconstruction model}

On the basis of the above analyses, a linear regression model was employed to reconstruct the history of JuneJuly 5-month scale SPEI variations since 1009 CE in the eastern part of the Qilian Mountains. The reconstruction model based on the entire instrumental period for year $t$ is

SPEI $_{6-7}=2.640 \times I-3.725$

where SPEI5 $5_{6-7}$ is the June-July 5-month scale SPEI and $I$ is tree-ring index for a given year. The model explained

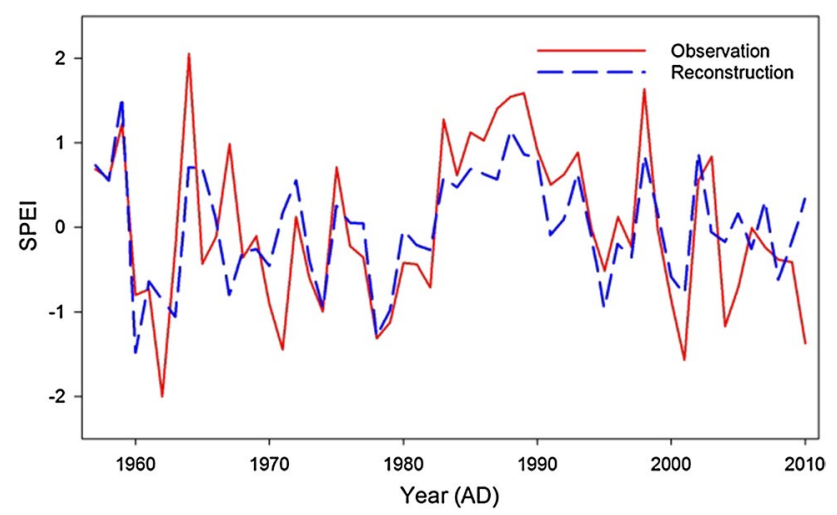

Fig. 6 Plots of observed (solid line) and estimated (dash line) JuneJuly 5-month scale SPEI for the common period from 1957 to 2010
$49.6 \%$ of the variance in the SPEI data $(48.6 \%$ after adjustment for loss of degrees of freedom) for the period from 1957 to 2010.

Figure 6 is a comparison of the reconstructed and observed SPEI during the common period and it indicates a generally good model fit. The instrumental dataset was split into two periods (1957-1983 and 1984-2010) to test the quality and stability of the calibration models (Fritts 1976; Cook and Kairiukstis 1990). The F value, r, ST and ST1 are all statistically significant, and RE and $\mathrm{CE}$ are both positive (Table 1), indicating that the regression model has been statistically validated.

\subsection{Reconstructed drought variation}

The reconstructed June-July SPEI is plotted in Fig. 7. The mean SPEI for the full reconstruction was -1.085 , and the standard deviation $\sigma$ was 0.848 . We defined wet or dry years as when the SPEI was greater or less than 1 SD from the mean, respectively. The full reconstruction contained 158 dry and 163 wet years, each accounting for about $16 \%$ of the total years (Table 2). The distribution of the drought years in each century is not equal. Dry years were more frequent in the fifteenth and seventeenth century, when 36 and 31 dry years are estimated to have occurred, respectively. Interestingly, the twentieth century had only 3 drought years. This feature is even more obvious for the wet years. More than a half of the wet years were clustered in the sixteenth (with 41 wet years) and the twentieth (with 43 wet years) centuries. In contrast, the fifteenth century did not have any wet years, and the seventeenth, eighteenth and nineteenth centuries had only two wet years in each. Many drought and wet extremes occurred in successive years. The longest period of consecutive drought years was 9 years (1638-1646), with 5 years in 1465-1469 and 1478-1482 in second place. The longest pluvial event spanned 12 years (1983-1994) and the second longest pluvial lasted 9 years (1530-1538).

The reconstructed drought series shows strong decadal to centennial scale variability. To emphasize the low-frequency variations of sustained droughts and pluvial periods,

Table 1 Calibration and verification statistics for the reconstruction models

\begin{tabular}{|c|c|c|c|c|c|c|c|c|c|}
\hline \multicolumn{2}{|l|}{ Calibration } & \multicolumn{8}{|c|}{ Verification } \\
\hline Period & $\mathrm{R}^{2}$ & $\overline{R_{\text {adj }}^{2}}$ & F value & Period & $\mathrm{r}$ & ST & ST1 & $\mathrm{RE}$ & $\mathrm{CE}$ \\
\hline 1957-1983 & 0.424 & 0.401 & 18.43 & 1984-2010 & 0.746 & $24+3-$ & $19+7-$ & 0.562 & 0.464 \\
\hline 1984-2010 & 0.557 & 0.539 & 31.39 & 1957-1983 & 0.651 & $19+8-$ & $21+5-$ & 0.450 & 0.329 \\
\hline 1957-2010 & 0.496 & 0.486 & 51.15 & & & & & & \\
\hline
\end{tabular}

$\mathrm{R}^{2}$ is the explained variance; $\mathrm{R}_{\mathrm{adj}}^{2}$ is the explained variance after adjustment for loss of degrees of freedom; $r$ is the Pearson's correlation coefficient; ST is the sign test; ST1 is the first difference sign test; RE is the reduction of error; CE is the coefficient of efficiency. F value, Pearson's correlation coefficient and sign test are significant at or above 0.05 level 


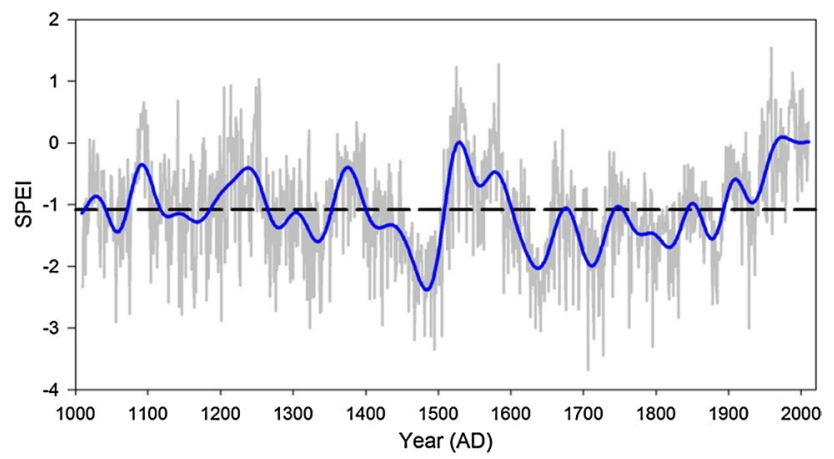

Fig. 7 Tree-ring-based SPEI reconstructions of the Eastern Qilian Mountains from 1009 to 2010, along with mean (the thick dashed line). To emphasize low-frequency variation the drought reconstruction was smoothed using a 50-year low-pass filter

Table 2 Droughts and pluvial in the last millennium

\begin{tabular}{lcc}
\hline Period & Drought & Pluvial \\
\hline 1009-1099 CE & 8 & 15 \\
12th century & 15 & 8 \\
13th century & 13 & 28 \\
14th century & 10 & 15 \\
15th century & 36 & 0 \\
16th century & 6 & 41 \\
17th century & 31 & 2 \\
18th century & 21 & 2 \\
19th century & 15 & 2 \\
20th century & 3 & 43 \\
2000-2010 CE & 0 & 7 \\
\hline
\end{tabular}

a 50-year low-pass filter was applied over the entire reconstruction to highlight multi-decadal to centennial variation. Several persistent (lasting more than 10 years) droughts with SPEI values below the long-term mean were identified: $1042-1071,1118-1185,1266-1353,1401-1508$, 1602-1671, 1680-1742, 1755-1842 and 1858-1892. Several persistent pluvials occurred in 1013-1041, 1072-1117, 1186-1265, 1354-1400, 1509-1601, 1743-1754, 18431857, and since 1894 (Fig. 7; Table 3).

\section{Discussion}

\subsection{Climate response}

The significant correlations between the tree-ring index and monthly precipitation are all positive, which means that the growth of Qilian Juniper in the studied area depends primarily on the moisture conditions. Because the study area is in the semi-arid region and sampling sites are located on
Table 3 The long-term droughts and pluvial in the last millennium

\begin{tabular}{lccc}
\hline Year & Duration & Magnitude & Intensity \\
\hline $1042-1071$ & 30 & -6.716 & -0.224 \\
$1118-1185$ & 68 & -7.472 & -0.110 \\
$1266-1353$ & 88 & -21.572 & -0.245 \\
$1401-1508$ & 108 & -63.759 & -0.590 \\
$1602-1671$ & 70 & -39.345 & -0.562 \\
$1680-1742$ & 63 & -31.457 & -0.499 \\
$1755-1842$ & 88 & -32.870 & -0.374 \\
$1858-1892$ & 35 & -10.144 & -0.290 \\
$1013-1041$ & 29 & 4.053 & 0.140 \\
$1072-1117$ & 46 & 19.887 & 0.432 \\
$1186-1265$ & 80 & 32.377 & 0.405 \\
$1354-1400$ & 47 & 19.952 & 0.425 \\
$1509-1601$ & 93 & 54.374 & 0.585 \\
$1743-1754$ & 12 & 0.425 & 0.035 \\
$1843-1857$ & 15 & 0.995 & 0.066 \\
$1893-2010$ & 118 & 81.252 & 0.689 \\
\hline
\end{tabular}

Magnitude portrays the cumulative severity of each event while the intensity indicates the average severity of each event

steep hillsides, the annual precipitation is low and the limited amount of water storage in the soil can hardly meet the trees' demand. Therefore, moisture is the main limiting factor for trees growing in this area. As expected, the significant correlations between the tree-ring index and temperature in current May is negative, because higher temperature would likely have enhanced potential evapotranspiration, decreased the moisture content of the soil, and thus limited tree growth. The negative correlation with previous August temperature is also significant, suggesting that some carbohydrates produced at the end of the previous growing season may have been incorporated into the current year's ring and poor conditions for photosynthesis at this time may have affected the production of carbohydrates.

The correlation coefficients between the tree-ring chronology and growing season SPEI also imply that the radial growth rate of Qilian juniper (J. przewalskii Kom.) in this area was constrained by water availability. The correlation coefficients with SPEI are higher than that with precipitation or temperature, indicating that the SPEI is a better indicator of the moisture than simply precipitation, as it considers both precipitation and temperature through evapotranspiration demand. The highest of correlations $(r>0.6)$ between the tree-ring chronology and the SPEI at different time scales were recorded at relatively short-time scales (from 2 to 6 months), which indicates that the tree growth in this area tends to respond to drought on a short time-scale.

Other dendroclimatic studies of ring width from the eastern Qilian Mountains indicate moisture sensitivity in other tree species. Drought response was also found in 


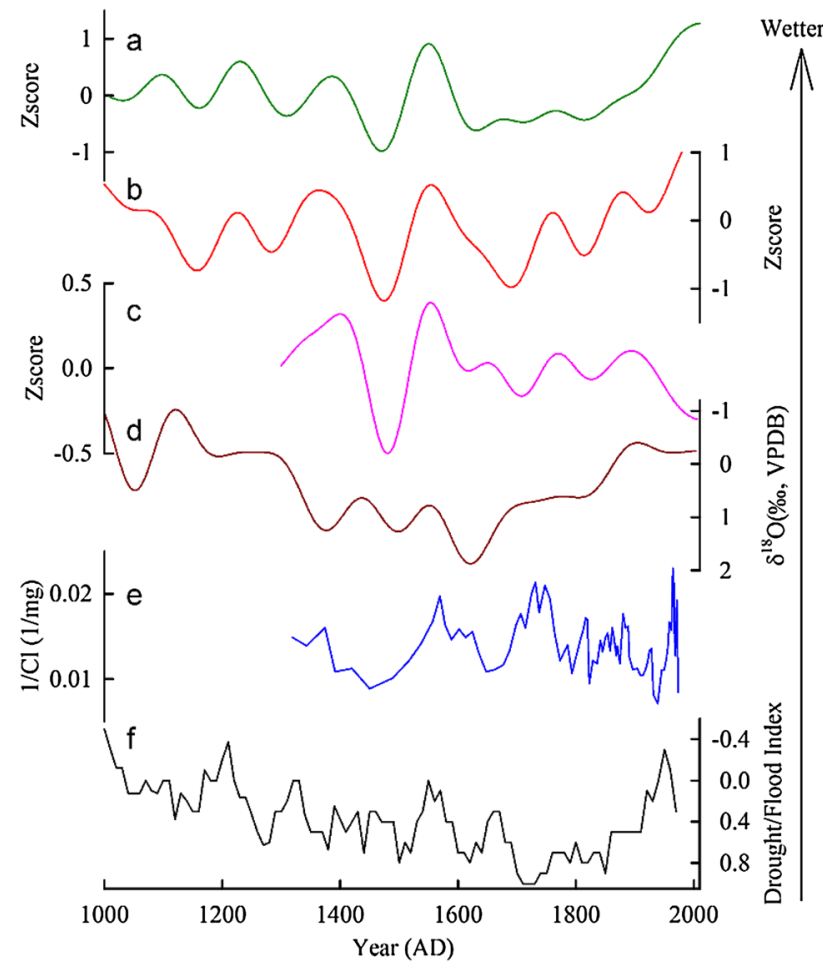

Fig. 8 Comparisons among Eastern Qilian Mountains drought severity reconstruction $(a)$, the precipitation reconstruction in the northeastern of the Tibetan Plateau (Yang et al. 2014) (b), the nearest grid in (Cook et al. 2010)'s monsoon Asian drought reconstruction dataset $(c)$, precipitation reconstruction derived from the speleothem $\delta^{18} \mathrm{O}$ from the Wangxiang Cave (Zhang et al. 2008) (d), groundwater recharge rate in the Badain Jaran Desert (Gates et al. 2008) (e), and historical documents records based Longxi precipitation reconstruction (Tan et al. 2008) (f). The curves in $a-d$ are smoothed using a 100 -year low-pass filter, and the $f$ is smoothed using a 5-point running average

Qinghai spruce (P. crassifolia) in the eastern Qilian Mountains (Deng et al. 2013; Gao et al. 2013), and Picea wilsonii in the Xinglong Mountain (Fang et al. 2009).

\subsection{Comparison with other hydroclimate reconstructions}

To validate our reconstruction, we compared our series with five other hydroclimate reconstructions of northeastern Tibetan Plateau from both tree-ring data and other proxy data (Fig. 8). These series used for comparison include the precipitation reconstructions for the northeastern Tibetan Plateau (Yang et al. 2014) (Fig. 8b), the nearest grid in (Cook et al. 2010)'s monsoon Asian drought reconstruction dataset (Fig. 8c), precipitation reconstruction derived from the speleothem $\delta^{18} \mathrm{O}$ from the Wangxiang Cave (Zhang et al. 2008) (Fig. 8d), groundwater recharge rate in the Badain Jaran Desert (Gates et al. 2008) (Fig. 8e), and the Longxi precipitation reconstruction based on historical documentary records (Tan et al. 2008) (Fig. 8f).
The eleventh to the middle of the thirteenth century was generally wet, with only two slight droughts at 1042-1071 and $1118-1185$ in our new reconstruction. This is consistent with the precipitation reconstructions for the northeastern Tibetan Plateau (Yang et al. 2014), the historical documentary reconstruction of Longxi precipitation (Tan et al. 2008), and low salinity in Qinghai Lake (Zhang et al. 2004). During this time, the Asian summer monsoon may have been enhanced as suggested by the speleothem $\delta^{18} \mathrm{O}$ from the Wangxiang Cave (Zhang et al. 2008).

The persistent drought in the fifteenth century (14001508) was the deepest and most profound drought in the last millennium (Table 3), including two 5-year droughts (1465-1469 and 1478-1482) and 39 dry years in all. This long drought period is widely reported in many tree-ring width based drought or precipitation reconstructions in northeastern Tibetan Plateau (Gou et al. 2014), including the source of the Yellow river (Gou et al. 2010), the Qaidam Basin (Zhang et al. 2003; Sheppard et al. 2004; Shao et al. 2005; Liu et al. 2006; Yang et al. 2014), the middle and west Qilian mountains (Yang et al. 2011a, b; Zhang et al. 2011; Sun and Liu 2012), and the nearest PDSI grid in (Cook et al. 2010)'s monsoon Asian drought reconstruction dataset. It is also recorded in various other paleoclimatic archives, and obvious in a tree-ring oxygen isotope based precipitation reconstruction from the Qaidam Basin (Wang et al. 2013). This dry period is also consistent with drought in Longxi (Tan et al. 2008), lower diffuse groundwater recharge rate in the Badain Jaran Desert (Gates et al. 2008), increased salinity in Qinghai Lake (Zhang et al. 2004), and lower total organic carbon in Kusai Lake (Liu et al. 2009). This drought was not limited to the northeastern Tibet Plateau and nearby areas. Many studies of southwest Asia (Anderson et al. 2002), northern Pakistan (Treydte et al. 2006) and India (Yadav 2010) also recorded this extended drought in the fifteenth century.

After the severe large-scale dry conditions in the fifteenth century, a sharp increase in moisture occurred. This prolonged pluvial persisted until the beginning of the seventeenth century, and has also been recorded in the nearest grid in MADA (Cook et al. 2010), the northeastern Tibetan Plateau (Yang et al. 2014), Badain Jaran Desert (Gates et al. 2008) and Longxi (Tan et al. 2008).

Almost three entire centuries, from early seventeenth century to the end of the nineteenth century, were characterized as persistent drought. It was separated into four multidecadal droughts by three short-term humid periods (1672$1679,1743-1754$ and 1843-1857), which were only slightly higher than average. The first two drought periods of the four are very outstanding in the entire reconstruction. The 1602-1671 CE drought, including the longest period of consecutive drought years (1638-1646), was also widespread in northwest China. This seventeenth century drought is also 
consistent with the low diffuse groundwater recharge rate in the Badain Jaran Desert (Gates et al. 2008) and high salinity in Qinghai Lake (Zhang et al. 2004). The negative impact of this severe drought has been proposed as one of the possible contributing factors to the decline of the Ming Dynasty (Zhang et al. 2008). The 1681-1740 CE drought was also reported in tree-ring width or oxygen isotope reconstructed precipitation in the Qaidam Basin (Zhang et al. 2003; Sheppard et al. 2004; Shao et al. 2005; Wang et al. 2013), and streamflow reconstructions for the Kherlen River (Davi et al. 2013), the Yeruu River (Pederson et al. 2013) and the Selenge River (Davi et al. 2006) in Mongolia.

Since 1894, a persistent positive trend in moisture has been recorded until present day. Wet conditions in the twentieth century were recorded in many other tree-ring based studies in the nearby regions, e.g., the middle Qilian Mountains (Yang et al. 2011b), the Qaidam Basin (Zhang et al. 2003; Sheppard et al. 2004; Liu et al. 2006; Shao et al. 2010; Yang et al. 2014), central eastern Tibet (Bräuning and Mantwill 2004), the Tienshan area (Li et al. 2006) and in western and northern Mongolia (Davi et al. 2009; Pederson et al. 2013). Ice core records from the Guliya and Dunde in northern Tibetan Plateau and Puruogangri in central Tibetan Plateau all show a wetting trend in the last century (Yao et al. 2008). Based on historical documents, Tan et al. (2008) also show an increasing trend in Longxi precipitation over the last century. A 700-year history of diffuse groundwater recharge in the Badain Jaran Desert also suggests the latter half of the twentieth century was wet (Gates et al. 2008). During this time, the Asian summer monsoon was more powerful as suggested by lower $\delta^{18} \mathrm{O}$ values from stalagmites (Wang et al. 2005; Zhang et al. 2008).

These new reconstructions of droughts and pluvials for the eastern Qilian Mountains for the past millennium are generally consistent with the previous hydroclimate reconstructions at the low frequency. However, there are also some inconsistencies among these records. For example, most of the series indicate that the climatic conditions have been relatively wet in the twentieth century, while the summer PDSI reconstruction derived from Cook et al. (2010) shows a drying trend. To explain the discrepancies, we plotted the tree-ring chronologies in the vicinity of our study area that have been used by Cook et al. (2010), and computed the correlation coefficients between the tree-ring chronologies located in the extent of the PDSI grid we used for comparison and the reconstructed PDSI during the calibration period (1951-1989). As shown in Fig. 9, there are only two tree-ring chronologies located in the extent of the PDSI grid that we used for comparison, and the correlations are not statistically significant at the $95 \%$ level for the PDSI gird we used for comparison during the calibration period. The searching radii used in the study is pretty large $(500,1,000,2,000$, and $3000 \mathrm{~km})$ for

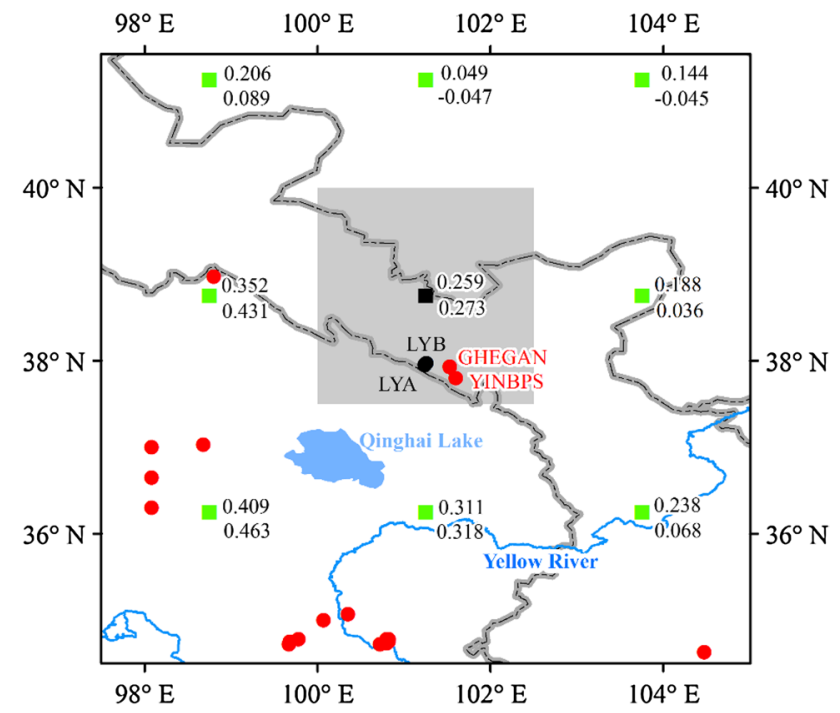

Fig. 9 Distribution of the tree-ring chronologies (red dots) near the study area used by Cook et al. (2010), and the correlations between the two nearby chronologies and the reconstructed PDSI (green square) by Cook et al. (2010) during the calibration period (19511989). The upper (lower) number is the correlation coefficient between the PDSI grid and GHEGAN (YINBPS). The sampling sites (black dots) in our study and the nearest PDSI grid (black square) to them are also labeled. The gray shadow square represent the extent of the nearest PDSI grid

the tree-ring chronologies selecting, some remote tree-ring chronologies may have been used to reconstruct the PDSI at some grids. On the other side, due to sparse observation stations and large variation of the landform in this remote area the PDSI index of the research area is not very accurate either, which may also lead to low correlation between the tree ring chronologies and PDSI in Cook's research. The very good agreement in the low frequency between the regional hydroclimate reconstructions and Cook et al. (2010)'s before the twentieth century indicate that, even for the regions without enough highly correlated local treering chronologies, Cook et al. (2010)'s still contains valuable information although some remote chronologies have been used. In conclusion, we think the discrepancies may be caused by the limited number of significantly correlated local tree-ring chronologies. This inconsistency suggests that further research effort to expand the tree-ring network is needed to update that kind of reconstruction.

\section{Conclusion}

A millennium-long tree-ring width chronology was developed in the eastern Qilian Mountains. Tree growth in this region was negatively and significantly correlated with May temperature and positively and significantly correlated with precipitation of May and June of the current year. The 
tree-growth is also significantly correlated with SPEI in June and July, especially at short time scales. A reconstruction of June-July 5-month scale SPEI for the eastern Qilian Mountains was developed back to $1009 \mathrm{CE}$, using a linear regression model and the reliable portion of the chronology. The eastern Qilian Mountains experienced several decadal scale droughts and pluvials over the last millennium, with a pronounced drought period during the fifteenth century and a significant and persistent wetting trend since late nineteenth century. The droughts and pluvials identified in our reconstruction are consistent with other studies nearby.

Acknowledgments The authors are very grateful to the two anonymous referees for their valuable comments and suggestions to improve the manuscript. This research is supported by the National Science Foundation of China (No. 41475067, No. 41171039 and No. 41401047). Yang Deng and Linlin Gao are also funded by the China Scholarship Council.

\section{References}

Anderson DM, Overpeck JT, Gupta AK (2002) Increase in the Asian southwest monsoon during the past four centuries. Science 297:596-599. doi:10.1126/science.1072881

Beguería S, Vicente-Serrano SM (2013) SPEI: calculation of the standardised precipitation-evapotranspiration index. Retrieved from http://cran.r-project.org/package=SPEI

Bräuning A, Mantwill B (2004) Summer temperature and summer monsoon history on the Tibetan plateau during the last 400 years recorded by tree rings. Geophys Res Lett 31:L24205. doi:10.102 9/2004GL020793

Chen F, Yu Z, Yang M et al (2008) Holocene moisture evolution in arid central Asia and its out-of-phase relationship with Asian monsoon history. Quat Sci Rev 27:351-364. doi:10.1016/j. quascirev.2007.10.017

Cook ER, Kairiukstis LA (1990) Methods of dendrochronology. Kluwer Academic, Dordrecht

Cook ER, Briffa KR, Meko DM et al (1995) The "segment length curse" in long tree-ring chronology development for palaeoclimatic studies. The Holocene 5:229-237. doi:10.1177/095968369500500211

Cook ER, Meko DM, Stahle DW, Cleaveland MK (1999) Drought reconstructions for the continental United States. J Clim 12:11451162. doi:10.1175/1520-0442(1999)012<1145:DRFTCU>2.0.CO;2

Cook ER, Anchukaitis KJ, Buckley BM et al (2010) Asian monsoon failure and megadrought during the last millennium. Science 328:486-489. doi:10.1126/science. 1185188

Cook ER, Krusic PJ, Melvin T (2013) Program RCSigFree: Version 43ptr05. Lamont-Doherty Earth Obs. Columbia Univ, Palisades

Davi NK, Jacoby GC, Curtis AE, Baatarbileg N (2006) Extension of drought records for central Asia using tree rings: West-central Mongolia. J Clim 19:288-299. doi:10.1175/JCLI3621.1

Davi NK, Jacoby GC, D'Arrigo RD et al (2009) A tree-ring-based drought index reconstruction for far-western Mongolia: 15652004. Int J Climatol 29:1508-1514. doi:10.1002/joc.1798

Davi NK, Pederson N, Leland C et al (2013) Is eastern Mongolia drying? A long-term perspective of a multidecadal trend. Water Resour Res 49:151-158. doi:10.1029/2012WR011834

Deng Y, Gou X, Gao L et al (2013) Aridity changes in the eastern Qilian Mountains since AD1856 reconstructed from tree-rings. Quat Int 283:78-84. doi:10.1016/j.quaint.2012.04.039
Droogers P, Allen R (2002) Estimating reference evapotranspiration under inaccurate data conditions. Irrig Drain Syst 16:33-45. doi:1 0.1023/A:1015508322413

Fang K, Gou X, Chen F et al (2009) Drought variations in the eastern part of northwest China over the past two centuries: evidence from tree rings. Clim Res 38:129-135. doi:10.3354/cr00781

Frank D, Esper J, Cook ER (2007) Adjustment for proxy number and coherence in a large-scale temperature reconstruction. Geophys Res Lett 34:L16709. doi:10.1029/2007GL030571

Fritts HC (1976) Tree rings and climate. Academic Press, London

Gao L, Gou X, Deng Y et al (2013) Dendroclimatic response of Picea crassifolia along an altitudinal gradient in the eastern Qilian Mountains, northwest China. Arct Antarct Alp Res 45:491-499. doi:10.1657/1938-4246-45.4.491

Gates JB, Edmunds WM, Ma J, Sheppard PR (2008) A 700-year history of groundwater recharge in the drylands of NW China. The Holocene 18:1045-1054. doi:10.1177/0959683608095575

Gou XH, Deng Y, Chen FH et al (2010) Tree ring based streamflow reconstruction for the Upper Yellow River over the past 1234 years. Chin Sci Bull 55:4179-4186. doi:10.1007/s11434-010-4215-Z

Gou XH, Deng Y, Chen FH et al (2014) Precipitation variations and possible forcing factors on the Northeastern Tibetan Plateau during the last millennium. Quat Res 81:508-512. doi:10.1016/j. yqres.2013.09.005

Holmes RL (1983) Computer-assisted quality control in tree-ring dating and measurement. Tree-ring Bull 43:69-78

IPCC (2013) Summary for policymakers. In: Stocker TF, Qin D, Plattner G-K et al (eds) Climate change 2013: the physical science basis. Contribution of working group I to the fifth assessment report of the Intergovernmental Panel on Climate Change. Cambridge University Press, Cambridge

Jones P, Hulme M (1996) Calculating regional climatic time series for temperature and precipitation: methods and illustrations. Int $\mathrm{J}$ Climatol 16:361-377. doi:10.1002/ (SICI)1097-0088(199604)16:4<361:AID-JOC53>3.0.CO;2-F

Li J, Gou X, Cook ER, Chen F (2006) Tree-ring based drought reconstruction for the central Tien Shan area in northwest China. Geophys Res Lett 33:L07715. doi:10.1029/2006GL025803

Liu X, Qin D, Shao X et al (2005) Temperature variations recovered from tree-rings in the middle Qilian Mountain over the last millennium. Sci China Ser D Earth Sci 48:521-529. doi:10.1360/03yd0063

Liu Y, An Z, Ma H et al (2006) Precipitation variation in the northeastern Tibetan Plateau recorded by the tree rings since $850 \mathrm{AD}$ and its relevance to the Northern Hemisphere temperature. Sci China Ser D Earth Sci 49:408-420. doi:10.1007/s11430-006-0408-3

Liu XQ, Dong HL, Yang XD et al (2009) Late Holocene forcing of the Asian winter and summer monsoon as evidenced by proxy records from the northern Qinghai-Tibetan Plateau. Earth Planet Sci Lett 280:276-284. doi:10.1016/j.eps1.2009.01.041

Melvin TM, Briffa KR (2008) A "signal-free" approach to dendroclimatic standardisation. Dendrochronologia 26:71-86. doi:10.1016/j.dendro.2007.12.001

Osborn TJ, Briffa KR, Jones PD (1997) Adjusting variance for sample size in tree-ring chronologies and other regional mean timeseries. Dendrochronologia 15:89-99

Pederson N, Leland C, Nachin B et al (2013) Three centuries of shifting hydroclimatic regimes across the Mongolian Breadbasket. Agric For Meteorol 178-179:10-20. doi:10.1016/j. agrformet.2012.07.003

R Core Team (2014) R: a language and environment for statistical computing. Retrieved from http://www.r-project.org/

Shao X, Huang L, Liu H et al (2005) Reconstruction of precipitation variation from tree rings in recent 1000 years in Delingha, Qinghai. Sci China Ser D Earth Sci 48:939-949. doi:10.1360/03yd0146 
Shao X, Xu Y, Yin ZY et al (2010) Climatic implications of a 3585year tree-ring width chronology from the northeastern QinghaiTibetan Plateau. Quat Sci Rev 29:2111-2122. doi:10.1016/j. quascirev.2010.05.005

Sheppard PR, Tarasov PE, Graumlich LJ et al (2004) Annual precipitation since $515 \mathrm{BC}$ reconstructed from living and fossil juniper growth of northeastern Qinghai Province, China. Clim Dyn 23:869-881. doi:10.1007/s00382-004-0473-2

Shi Y, Shen Y, Kang E et al (2007) Recent and future climate change in northwest China. Clim Change 80:379-393. doi:10.1007/ s10584-006-9121-7

Stokes MA, Smiley TL (1968) An introduction to tree-ring dating. University of Chicago Press, Chicago, IL

Sun J, Liu Y (2012) Tree ring based precipitation reconstruction in the south slope of the middle Qilian Mountains, northeastern Tibetan Plateau, over the last millennium. J Geophys Res 117:D08108. doi:10.1029/2011JD017290

Tan LC, Cai YJ, Yi L et al (2008) Precipitation variations of Longxi, northeast margin of Tibetan Plateau since AD 960 and their relationship with solar activity. Clim Past 4:19-28. doi:10.5194/ cp-4-19-2008

Treydte KS, Schleser GH, Helle G et al (2006) The twentieth century was the wettest period in northern Pakistan over the past millennium. Nature 440:1179-1182. doi:10.1038/nature04743

Vicente-Serrano SM, Beguería S, López-Moreno JI (2010) A multiscalar drought index sensitive to global warming: the standardized precipitation evapotranspiration index. J Clim 23:16961718. doi:10.1175/2009JCLI2909.1

Wang Y, Cheng H, Edwards RL et al (2005) The Holocene Asian monsoon: links to solar changes and North Atlantic climate. Science 308:854-857. doi:10.1126/science.1106296

Wang W, Liu X, Xu G et al (2013) Moisture variations over the past millennium characterized by Qaidam Basin tree-ring $\delta^{18} \mathrm{O}$. Chin Sci Bull 58:3956-3961. doi:10.1007/s11434-013-5913-0

Wentz FJ, Ricciardulli L, Hilburn K, Mears C (2007) How much more rain will global warming bring? Science 317:233-235. doi:10.1126/science.1140746
Yadav RR (2010) Long-term hydroclimatic variability in monsoon shadow zone of western Himalaya, India. Clim Dyn 36:14531462. doi:10.1007/s00382-010-0800-8

Yang B, Qin C, Bräuning A et al (2011a) Rainfall history for the Hexi Corridor in the arid northwest China during the past 620 years derived from tree rings. Int J Climatol 31:1166-1176. doi:10.1002/joc. 2143

Yang B, Qin C, Shi F, Sonechkin DM (2011b) Tree ring-based annual streamflow reconstruction for the Heihe River in arid northwestern China from AD 575 and its implications for water resource management. The Holocene 22:773-784. doi:10.1177/0959683611430411

Yang B, Qin C, Wang J et al (2014) A 3,500-year tree-ring record of annual precipitation on the northeastern Tibetan Plateau. Proc Natl Acad Sci USA 111:2903-2908. doi:10.1073/ pnas. 1319238111

Yao T, Duan K, Xu B et al (2008) Precipitation record since AD 1600 from ice cores on the central Tibetan Plateau. Clim Past 4:175180. doi:10.5194/cp-4-175-2008

Zhang Q, Cheng G, Yao T et al (2003) A 2,326-year tree-ring record of climate variability on the northeastern Qinghai-Tibetan Plateau. Geophys Res Lett 30:GL017425. doi:10.1029/200 3GL017425

Zhang E, Shen J, Wang S et al (2004) Quantitative reconstruction of the paleosalinity at Qinghai Lake in the past 900 years. Chin Sci Bull 49:730-734. doi:10.1007/BF03184273

Zhang P, Cheng H, Edwards RL et al (2008) A test of climate, sun, and culture relationships from an 1810-year Chinese cave record. Science 322:940-942. doi:10.1126/science.1163965

Zhang Y, Tian Q, Gou X et al (2011) Annual precipitation reconstruction since AD 775 based on tree rings from the Qilian Mountains, northwestern China. Int J Climatol 31:371-381. doi:10.1002/ joc. 2085 